\section{Editorial}

Check for updates

\title{
Vicious Cycle between Brain and Muscle
}

\section{Beom Sun Chung ${ }^{(1)}$}

Department of Anatomy, Ajou University School of Medicine, Suwon, Korea

- See the article "Understanding the Relationship between Low Muscle Mass and Depressed Mood in Korean Girls" in volume 34 number 7, e51.
Received: Feb 27, 2019

Accepted: Feb 27, 2019

Address for Correspondence:

Beom Sun Chung, MD

Department of Anatomy, Ajou University

School of Medicine, 164 World Cup-ro,

Yeongtong-gu, Suwon 16499, Republic of

Korea.

E-mail: bschung@ajou.ac.kr

(C) 2019 The Korean Academy of Medical

Sciences.

This is an Open Access article distributed under the terms of the Creative Commons Attribution Non-Commercial License (https:// creativecommons.org/licenses/by-nc/4.0/) which permits unrestricted non-commercial use, distribution, and reproduction in any medium, provided the original work is properly cited.

ORCID iDs

Beom Sun Chung (iD)

https://orcid.org/0000-0002-3644-9120

Disclosure

The author has no potential conflicts of interest to disclose.

Dro

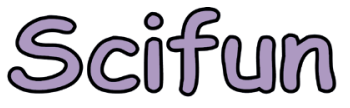

BS Chung (anatomy.co.kr)

Vicious cycle between brain and muscle

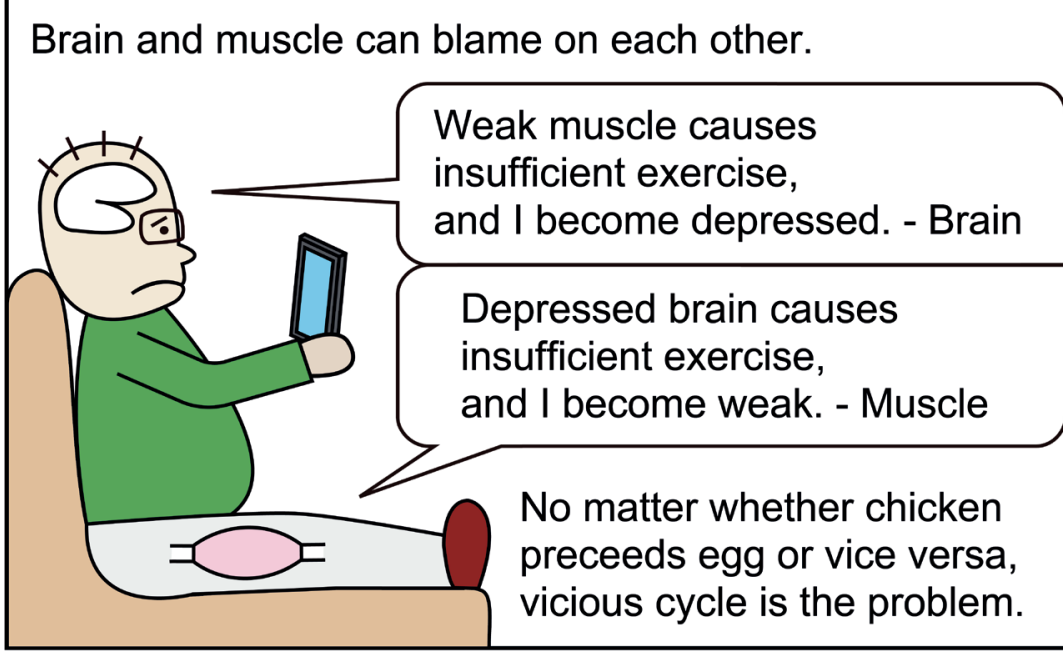

The vicious cycle must be broken either by brain

After treating depression, exercise is preferred.

- Brain

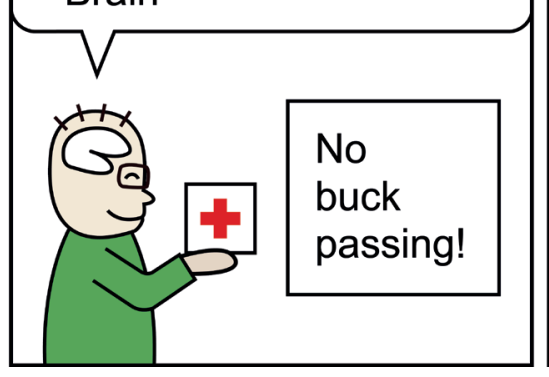

or by muscle.

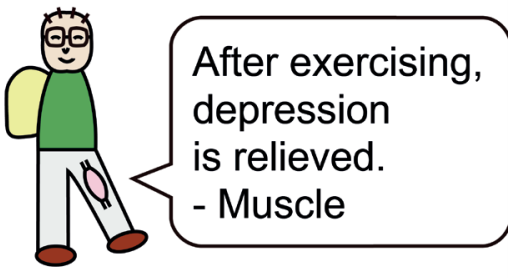

No matter whether mental health comes before physical health or vice versa, breaking vicious cycle is the solution. 